\title{
2008—down, but not out
}

Walter Yang

The biotech sector received $\$ 20$ billion less in funding in 2008 than the previous year. Public equity markets were particularly hard hit, with IPOs (initial public offerings), follow-ons and PIPEs (private investment in public equity) all down 35\% or more compared to 2007.

\section{Stock market performance}

The overall markets were off more than $30 \%$ on the year, whereas the BioCentury 100 index was down 20\%.

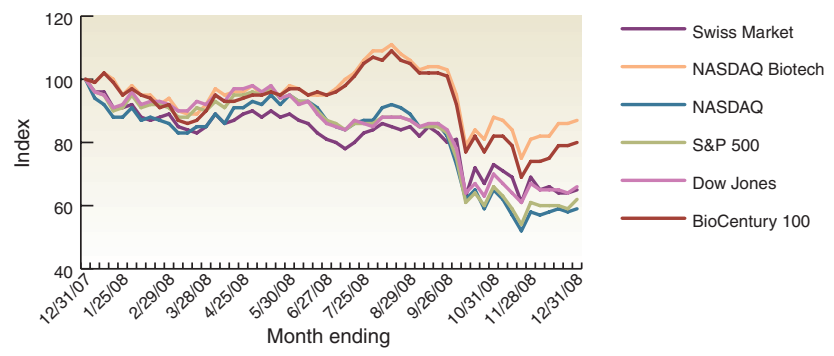

\section{Global biotech venture capital (VC) investment}

Private companies raised about $\$ 5$ billion in 2008 , similar to levels seen in 2004-2006.

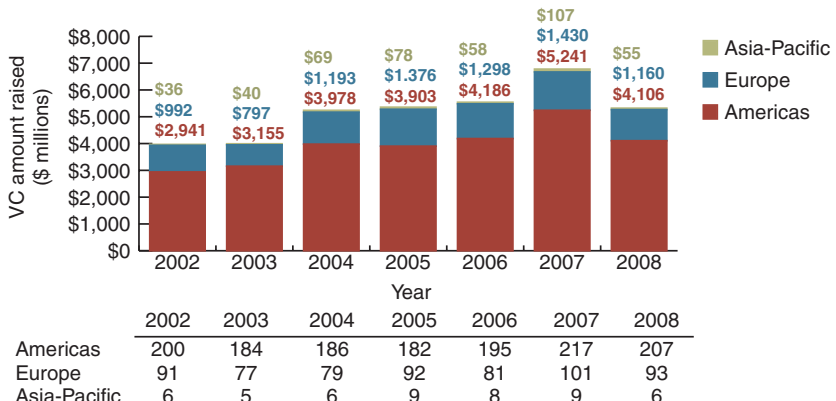

Table indicates number of $\mathrm{VC}$ investments. Source: $\mathrm{BCIQ}$ : BioCentury Online Intelligence

Notable 2008 deals

\begin{tabular}{|c|c|c|c|c|}
\hline IPOs & Company (lead underwriters) & $\begin{array}{c}\text { Amount } \\
\text { raised } \\
\text { (\$ millions) }\end{array}$ & $\begin{array}{c}\text { Percent } \\
\text { change in } \\
\text { stock price } \\
\text { since offer }\end{array}$ & $\begin{array}{l}\text { Date } \\
\text { completed }\end{array}$ \\
\hline & MoIMed (Banca IMI, Societe Generale) & $\$ 85.4$ & $-50 \%$ & 29-Feb \\
\hline & Ipsogen (Bryan, Garnier \& Co.) & $\$ 18.6$ & $-19 \%$ & 10-Jun \\
\hline & $\mathrm{PCI}$ Biotech (Fondsfinans) & $\$ 12.0$ & $-45 \%$ & 10-Jun \\
\hline & Fluorotechnics & $\$ 7.0$ & $-1 \%$ & 24-Oct \\
\hline & Bioheart (Dawson James) & $\$ 5.8$ & $-81 \%$ & 19-Feb \\
\hline & Genera Biosystems (Domain Capital) & $\$ 4.8$ & $-52 \%$ & 21-May \\
\hline \multirow[t]{8}{*}{$\begin{array}{l}\text { Venture } \\
\text { capital }\end{array}$} & Company (lead investors) & $\begin{array}{l}\text { Amount } \\
\text { raised } \\
\text { (\$ millions) }\end{array}$ & $\begin{array}{l}\text { Round } \\
\text { number }\end{array}$ & Date closed \\
\hline & OncoMed (Adams Street Partners) & $\$ 169.0$ & 2 & 12-Dec \\
\hline & Portola (No lead) & $\$ 130.0$ & 3 & 9-Jul \\
\hline & $\begin{array}{l}\text { Pacific Biosciences (Deerfield, Intel } \\
\text { Capital) }\end{array}$ & $\$ 100.0$ & 5 & 14-Jul \\
\hline & $\begin{array}{l}\text { Radius Health (MPM Capital, Wellcome } \\
\text { Trust, MPM Bio IV NVS) }\end{array}$ & $\$ 82.5$ & 3 & 20-Nov \\
\hline & Ganymed (ATS Beteiligungsverwaltung) & $\$ 82.2$ & 4 & 18-Nov \\
\hline & Proteolix (Nomura Phase4 Ventures) & $\$ 79.0$ & 3 & 8-Sep \\
\hline & $\begin{array}{l}\text { Gemin X (Caxton Advantage Life Sciences } \\
\text { Fund, Caxton Global) }\end{array}$ & $\$ 76.0$ & 3 & 30-Jun \\
\hline
\end{tabular}

Venture financings were also off one-fifth from the $\$ 6.8$ billion posted in 2007. Funding from partnerships came in at $\$ 20$ billion, compared with $\$ 22$ billion for 2007. In general, biotech indexes performed better than the Dow Jones Industrial Average and Standard \& Poor's 500.

\section{Global biotech industry financing}

Including partnership promises to US companies, biotech financing dropped to $\$ 34$ billion from $\$ 53$ billion in 2007.

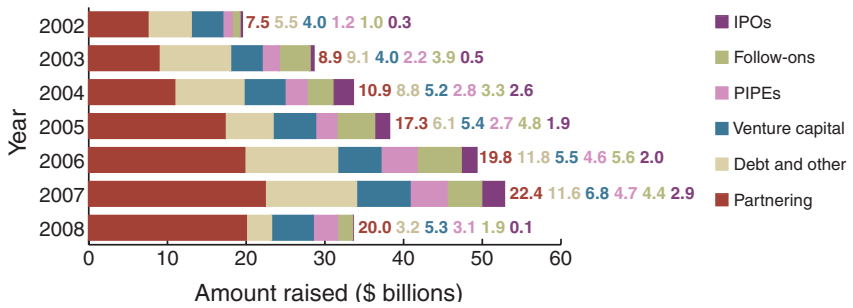

PIPEs, private investment in public equity; IPOs, initial public offerings. Source: $B C I Q$ : BioCentury Online Intelligence, Burrill \& Co.

\section{Global biotech initial public offerings (IPOs)}

Only six IPOs were completed in 2008 , and only one of those listed in the US.

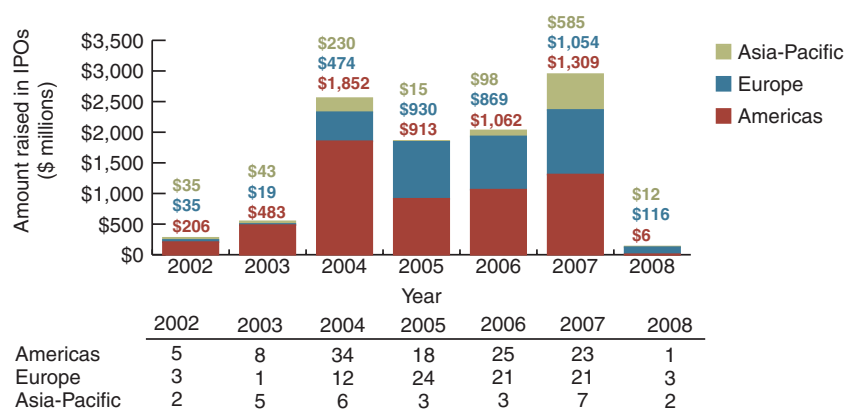

Table indicates number of IPOs. Source: BCIQ: BioCentury Online Intelligence

\begin{tabular}{|c|c|c|c|c|c|c|}
\hline \multirow[t]{7}{*}{$\begin{array}{l}\text { Mergers and } \\
\text { acquisitions }\end{array}$} & \multicolumn{2}{|l|}{ Target } & \multicolumn{2}{|c|}{ Acquirer } & $\begin{array}{c}\text { Value } \\
\text { (\$ millions) }\end{array}$ & $\begin{array}{c}\text { Date } \\
\text { announced }\end{array}$ \\
\hline & \multicolumn{2}{|l|}{ Genentech } & \multicolumn{2}{|l|}{ Roche } & $\$ 43,700$ & 21-Jul \\
\hline & \multicolumn{2}{|l|}{ Millennium } & \multicolumn{2}{|c|}{ Takeda } & $\$ 8,200$ & 10-Apr \\
\hline & \multicolumn{2}{|c|}{ Applied Biosystems } & \multicolumn{2}{|c|}{ Invitrogen } & $\$ 6,700$ & 12-Jun \\
\hline & \multicolumn{2}{|l|}{ ImClone } & \multicolumn{2}{|c|}{ Eli Lilly } & $\$ 6,500$ & 6-Oct \\
\hline & \multicolumn{2}{|l|}{ LifeCell } & \multicolumn{2}{|c|}{ Kinetic Concepts } & $\$ 1,700$ & 7-Apr \\
\hline & Speedel & & \multicolumn{2}{|c|}{ Novartis } & $\$ 900$ & 10-Jul \\
\hline \multicolumn{7}{|c|}{ Licensing /collaboration } \\
\hline Researcher & Investor & \multicolumn{2}{|c|}{$\begin{array}{c}\text { Value } \\
\text { (\$ millions) }\end{array}$} & \multicolumn{3}{|c|}{ Deal description } \\
\hline Actelion & GlaxoSmithKline & \multicolumn{2}{|c|}{$\$ 3,246.8$} & \multicolumn{3}{|c|}{$\begin{array}{l}\text { Co-develop and co-commercialize phase } 3 \text { insomnia } \\
\text { compound almorexant outside of Japan }\end{array}$} \\
\hline Isis & Genzyme & \multicolumn{2}{|c|}{$\$ 1,900.0$} & \multicolumn{3}{|c|}{$\begin{array}{l}\text { Develop mipomersen and follow-on compounds to } \\
\text { treat high cholesterol }\end{array}$} \\
\hline Acceleron & Celgene & \multicolumn{2}{|c|}{$\$ 1,878.0$} & \multicolumn{3}{|c|}{$\begin{array}{l}\text { Jointly develop and commercialize ACE-011 to } \\
\text { treat cancer; option for three other programs }\end{array}$} \\
\hline Archemix & GlaxoSmithKline & \multicolumn{2}{|c|}{$\$ 1,427.5$} & \multicolumn{3}{|c|}{$\begin{array}{l}\text { Develop and commercialize aptamer therapeutics to } \\
\text { treat inflammatory diseases }\end{array}$} \\
\hline Amgen & Takeda & \multicolumn{2}{|c|}{$\$ 1,177.0$} & \multicolumn{3}{|c|}{$\begin{array}{l}\text { Received Japanese rights to } 12 \text { compounds and } \\
\text { partnered to develop motesanib }\end{array}$} \\
\hline $\begin{array}{l}\text { PDL } \\
\text { (now } \\
\text { Facet) }\end{array}$ & Bristol-Myers & \multicolumn{2}{|c|}{$\$ 1,155.0$} & \multicolumn{3}{|c|}{$\begin{array}{l}\text { Develop and commercialize multiple myeloma } \\
\text { monoclonal antibody (mAb) elotuzumab } \\
\text { (HuLuc63); option to include PDL241 }\end{array}$} \\
\hline Exelixis & Bristol-Myers & \multicolumn{2}{|c|}{$\$ 1,000.0$} & \multicolumn{3}{|c|}{$\begin{array}{l}\text { Develop and commercialize phase } 3 \text { XL184 and } \\
\text { phase } 1 \text { compound XL28 }\end{array}$} \\
\hline Alnylam & Takeda & \multicolumn{2}{|c|}{$>\$ 1,000.0$} & \multicolumn{3}{|c|}{$\begin{array}{l}\text { Five-year collaboration to develop RNA interfer- } \\
\text { ence therapeutics }\end{array}$} \\
\hline
\end{tabular}

Walter Yang is research director at BioCentury 